\title{
A perfect storm or an imperfect supply chain? The U.S. supply chain crisis
}

\author{
Paul Kent ${ }^{1} \cdot$ Hercules Haralambides ${ }^{2,3}$
}

Accepted: 31 January 2022 / Published online: 16 February 2022

(C) The Author(s), under exclusive licence to Springer Nature Limited 2022

There is a classic episode on YouTube of the old American show "I Love Lucy". In it, Lucy and her best friend Ethel go to work wrapping candies on an assembly line. The line keeps speeding up with the candies coming closer together and, as they keep getting farther and farther behind, Lucy and Ethel scramble harder and harder to keep up, finally eating the candies and placing them in their clothes so as to give the perception they are catching up. But in their ill-fated effort, Lucy says "I think we're fighting a losing game". Indeed, Lucy's and Ethel's situation is a reflection of the crisis we have in our supply chains today; they both became supply chain bottlenecks with their factory's production decreasing and product availability diminished.

The supply chain crisis today is fueled in part by economic stimulus packages, changes in household expenditure patterns, and the resulting upward e-commerce growth. Eighty-five percent of U.S. households received stimulus payments, with many spending their payments on e-commerce goods. Additionally, official encouragements to stay at home, not travel, and refrain from gathering in groups in restaurants, gyms, and movie theaters led families to shift their discretionary expenditures from travel and leisure to home improvements and electronics. McKinsey reports that in the U.S. alone, 2020 e-commerce sales as a percent of retail sales reached slightly over $32 \%$, from $15 \%$ a year earlier. Of course, this was not only a U.S. phenomenon; UNCTAD reports that in 2020, when many countries were reeling from the pandemic in the year's first quarter, global e-commerce as a percent of total retail sales increased from 16\% in 2019 to $19 \%$ in 2020, with the United Kingdom, Korea, and China e-commerce sales increasing to at least 23\% of retail sales in 2020.

Simply put, the disruptions we are witnessing today in the form of blockages, port congestion, lack of goods, equipment and labor and, above all, global inflation and skyrocketing freight rates are just a textbook case of Keynesian excess demand vis à

Paul Kent

pkent@megconsulting.com

1 Monument Economics Group, 1000 Wilson Blvd, Ste 2650, Arlington, VA 22209, USA

2 School of Maritime Economics and Management, Dalian Maritime University, Dalian, China

3 The Sorbonne Center for Economics (CES), Paris 1 University, Panthéon Sorbonne, Paris, France 
vis an aggregate supply which kept declining for more than a year. The latter decline was manifested by factory closures in China and elsewhere, and lack of labor due to quarantines, lockdowns, and home isolation. No doubt, supply will again oblige at no small measure, but supply adjustments take time and they usually overshoot. The rollercoaster of the business cycle is all too well known, particularly in international shipping.

The surge in e-commerce and hence import activity arrived to a U.S. logistics system that could not accommodate it. Many have suggested that perfect storm conditions have created supply chain constraints. On the contrary, we believe that an imperfect supply chain, governed by the just-in-time (JIT) logistics paradigm, created the problems we have today. JIT and lean logistics practices encourage asset operators and logistics service providers to reduce slack in the system, in order to avoid added capital costs and improve the bottom line. There is nothing new here either; we are just watching again scenes of the same old movie called excruciating competition, leading to an unconditional preoccupation with cutting costs. Logistics has become, for years now, the 'new normal' and way of life. It is difficult to imagine today a young person physically visiting a store to buy a sweater or a pair of shoes or, to that effect, a cup of coffee. But logistics, aiming at minimizing inventory costs, depends critically on efficient transportation systems. For instance, in a reliable transportation system, we know precisely what time we need to leave home to make it to the airport. But if taxis are frequently on strike, rail under continuous maintenance, or security controls at airports a mess, we need to leave home an hour earlier. And this hour is 'our' inventory cost. In the Netherlands, as in many other countries, a small car accident on the highway during morning peak hours can cause havoc, with thousands of motorway kilometers totally congested. One of the most advanced transportation systems, that of the Netherlands, is not resilient to disruption and it could easily come to a standstill because it has no built-in remedial mechanisms.

The capabilities of marine terminals and warehouses, as another example, are measured in part by the extent of capacity utilization. Industry has established utilization thresholds that, when reached, would trigger investments in facility expansion or more productive technologies to maintain the needed slack in the asset to ensure resilience. Simple queuing theory, for example, tells us that berth utilization in container terminals generally should not exceed $65-75 \%$ and $80-85 \%$ for warehousing. Exceeding these thresholds raises the risk of congestion, leading to greater operational costs by terminal, warehouse, and vessel operators and their customers. It is worth noting that, in today's highly competitive environment of container terminals, combined with the footloose nature of the container, 'some' excess terminal capacity is an operational necessity (and thus an added cost), rather than evidence of inefficiency. While U.S. ports received the brunt of attention to supply chain woes, it is useful to holistically explore their causes and potential solutions. 


\section{Container shipping industry}

Let's start with the container shipping industry, which carries the preponderance of merchandise goods. In $2017,80 \%$ of liner shipping capacity became concentrated in three ocean shipping alliances, known as the $2 \mathrm{M}$ Alliance, THE Alliance, and OCEAN Alliance. The three alliances currently represent about $90 \%$ of global container trade volume. So both trade volume carried by alliance containerships and their capacity might appear highly concentrated in antitrust terms, if one were to take, mistakenly, global trade as the relevant market.

The U.S. Department of Justice (DOJ) recognized the threat of anticompetitive behavior, when it reviewed the alliance agreements. As an agency charged with antitrust enforcement, the DOJ aims to protect the public from a reduction in competition caused by agreements that lead to unreasonable market power, that is, the power to increase price or reduce output. The OCEAN Alliance agreement indicated that parties to it could take any actions needed for capacity rationalization, effectively allowing them to reduce output, something they do through space-sharing arrangements. The net effect is that the carrier industry can reduce its risk of excess capacity; in so doing, it is argued, it can lower its costs, although there is no guarantee or proof that the industry shares these savings with consumers, as the European Consortia Regulation requires. Setting cost aside, we believe that capacity was so tightly managed that the industry did not have sufficient flexibility to accommodate the surge in demand. Indeed, the DOJ urged the U.S. Federal Maritime Commission (FMC) to enjoin the OCEAN Alliance agreement.

\section{Container evacuations from the port}

Carriers need to meet their scheduled port calls, yet are unable to do so because of the log jam at major ports, particularly in China and Los Angeles/Long Beach. During the days of Liner Conferences, but also later with Alliances, carriers used to incorporate sufficient slack time in their itineraries to ensure they met their scheduled arrivals and departures. Typically, marine terminals have vessel windows for carrier port calls and delayed arrivals or departures can create havoc in a terminal's operations. In the Port of Los Angeles/Long Beach, there are currently more than 100 ships in the queue waiting about 23 days for berth availability. The queues effectively remove vessels from the market, which leads to the higher freight rates we are currently observing. Indeed, carriers have canceled ports of call or even entire voyages (referred to as blank sailings and blanking a string, respectively) to catch up on their service routings.

There are several reasons for the long vessel queues at ports, but they primarily concern the port's inability to expeditiously evacuate containers, leading to terminal capacity shortages. Shortages in port labor, truck drivers, chassis, and warehousing contribute to this problem, bogging down the flow of containers to and from the port's marine terminals. In such scenarios, many ports were forced 
to search for solutions on an ad hoc basis because, as it seems, supply chain system contingency response plans were not in place to address supply chain disruptions holistically.

For example, secondary ports such as Hueneme, about an hour's drive from the Port of Los Angeles/Long Beach, are being called into service to provide complementary capacity; the shipping industry is transshipping containers in Panama for routings on smaller vessels to Hueneme, and the small ships carrying reefer containers, already calling Hueneme, are also taking on dry containers in their calls there. These actions are intended to help mitigate the congestion problem in Los Angeles/Long Beach. While Hueneme does not have the channel draft for accommodating the large capacity vessels that call Los Angeles/Long Beach, it may also be worth exploring the possibility of discharging containers from anchored vessels onto barges, a concept similar to the midstreaming operation deployed in Hong Kong. The discharge operation can be done by four barge-mounted cranes at a rate of about 8 moves per crane-hour. Once discharged from vessels, containers could then be shipped unhindered by navigation constraints to secondary ports and discharged using relatively cheap reach stackers, decreasing cargo handling demand at the berths of congested ports.

Quick evacuation of containers from the port is also stymied by shortages in container storage areas. All around the Los Angeles metropolitan region, containers are seen scattered throughout the land, on streets, and outside warehousing/ distribution yards, which have no more space. This is the case despite the carriers shipping empty containers to Asia where they command much higher prices vis a vis those normally paid by US exporters. As a matter of fact, it was this lack of container availability for US exporters that led to recent shipper complaints to the FMC. Many months after signs of the impending congestion appeared, the Port of Los Angeles is making available two unfinished facilities for storing empty containers and is planning a container storage lot. While these will help de-clutter the container terminals, it is worth noting that the planned storage lot will not become reality without review by nearly 20 government bodies; still, the review was expected to be completed by the end of January 2022. Having said this, an existing contingency response plan for handling disruptions would have identified such areas for storage use with the necessary approvals already secured from relevant authorities.

As a temporary measure, it would seem large-scale parking lots in Los Angeles, of which there are many, could be enlisted for buffer (short-term) storage. There are about 12 Walmart Supercenters, 15 Sam's Clubs, 17 Home Depots, 25 Lowes, and 30 Costcos in Los Angeles County. Real estate investor CBRE indicates that most cities require five parking spaces per 1000 square feet of retail space, meaning that there are an awful lot of parking spaces that are increasingly unused as e-commerce sales rise. Many of the big box stores already store containers carrying goods for stock replenishment. Perhaps the big box store parking lots, as part of the noted contingency response plan, can be used (even for a fee) to allow short-term (overnight) buffer storage of containers in times of supply chain emergencies. 


\section{Warehousing constraints}

In addition to container storage constraints, cargo owners are encountering shortages in warehousing. Logistics facilities investment group Prologis reports that warehousing vacancy rates have been on a general decline since their high of about $10 \%$ vacancy in 2009 to only $4.7 \%$ in first quarter 2021 . Warehouse space vacancy rates are even lower in certain logistics hubs, with CBRE reporting vacancy rates for the third quarter 2021 as low as 1\% for Los Angeles, $1.9 \%$ in Boston and Charleston (South Carolina), 2.4\% in New Jersey, and only $0.7 \%$ at Inland Empire, the largest warehouse and distribution hub in the United States. Moreover, average warehouse utilization rates have hovered around $85 \%$ for the past 5 years, thus exhibiting a congestion risk well before the current supply chain crisis.

\section{Trucking industry constraints}

The American Transportation Research Institute reports an all-time high in the shortage of truck drivers and the shortage has been the number one industry issue identified in its past five annual surveys. The U.S. trucking industry has identified the recruitment of 18-20 year old individuals as a priority, in part to replace an aging truck driver workforce (30\% of drivers are 55 or older). However, according to U.S. career planning firm Zippia, only $9.4 \%$ of drivers are women, $16.7 \%$ Hispanic or Latino, $12.1 \%$ Black or African American, and 2.9\% Asian. It would seem, therefore, that recruitment from these cohorts would offer a potentially rich source of drivers if requirements unique to them were understood. Surveys by the Women in Trucking Association, for example, showed that about $63 \%$ of women professional drivers surveyed believe that a same-gender training program would encourage more women to pursue truck driving careers.

Overall, truck drivers work under difficult conditions. Their compensation compares unfavorably with other industry positions; they are isolated from family members for extended periods of time, and many parking and rest areas are full, forcing drivers to park on roadsides or access ramps to avoid driving beyond hours-of-service restrictions. Truck driver cabs, if designed with $\mathrm{RV}$-like attributes, can be more accommodating if a family member or partner accompanies drivers on their trips. A web-based rest stop reservation platform can also be offered for drivers to reserve spaces in advance or during their trips so they can better plan their journeys and make rest adjustments along the way. Finally, compensation packages can be more innovatively designed, with driver safety, productivity, and performance bonuses offered along with enhanced health and retirement benefits. In short, the pandemic brought to the surface the structural problems of one of the U.S. economy's most important industries, requiring remedial policy interventions.

The U.S. trucking industry in the port areas has also been hit by low availability of chassis. Trucker compensation suffers from delayed turn time due to chassis 
unavailability as truckers are compensated on the number of loads moved. In the U.S. today, the chassis industry is dominated by two international chassis companies, created when the ocean carriers divested their chassis businesses. Ocean carriers encouraged companies to buy their chassis by providing contracts to the new chassis companies. These "legacy" contracts mean that the shipping lines call the shots as to which chassis the trucking companies use. This also means there is a market entry barrier to new chassis companies vying for the market due to shipping line commitments via the legacy contracts to the two dominant firms. Even before COVID, there was evidence that the number of chassis has not kept pace with cargo growth. Hence, as is the case with liner shipping capacity shortages, insufficient capacity also rules the state of the chassis industry in some markets.

\section{Will shifting supply chains solve the problem?}

In addition to the 'new normal' ushered in by COVID, changes in trade agreements, disdain for consumerism in many parts of the developed world, switch of consumer behavior from goods to services, 3D printing advances, and more are likely to reduce transport distances and induce companies to shift some or all production capacity away from China to closer manufacturing hubs. COVID is a stark revelation to companies that managing supply chain risk is paramount; supply chain agility and risk have supplanted cheap labor costs as the most important criteria for industry location decisions.

To some degree, we have already seen a shift in supply chains, with AT Kearney declaring 2019 to have the highest re-shoring index they have ever calculated. Likely caused by U.S. corporate tax reductions and the China trade dispute, U.S. companies shifted production either via re-shoring or near-shoring. For example, according to the U.S Bureau of Census, China exports of electronic apparatuses to the U.S. declined $19.5 \%$ in 2019 while Vietnam's electronic apparatus exports to the U.S. increased $72.9 \%$.

Re-shoring and near-shoring probably mean some shifting of trade flows from one U.S. coast to another-the U.S. East Coast is likely, for example, to see larger volumes from Vietnam, as Vietnam and its neighboring countries to its west are generally inclined to ship freight via the Suez Canal and across the Atlantic. In a COVID environment, U.S. companies have suffered the consequences of overreliance on a limited number of supply chains and hence are considering a regionalization or proximity-to-market approach to establishing supply chains. AT Kearney reports that $52 \%$ of surveyed U.S. manufacturing executives indicated an increase in the sourcing of manufactured products from the U.S. in response to COVID-related disruptions, while $17 \%$ indicated an increase in the sourcing of products from nearshore countries (e.g., Mexico and Canada). While we can expect greater utilization of U.S. Gulf and East Coast ports due to shifting of supply chains, we are also likely to see more freight traffic on the U.S.-Mexican 
border. The extent of U.S. manufacturer re-shoring will also have an impact on U.S. port throughput.

\section{Recommendations}

It is ironic that today's Los Angeles/Long Beach congestion issues are often referred to as a perfect storm; the ports' congestion crisis in 2014, attributed to mega-ships, truck driver shortages, and a broken chassis system, was also referred to, among certain transport circles, as a perfect storm. One must wonder why any lessons learned back then are not relevant today. The Weinberger-Powell "once burned, twice cautious" doctrine comes to mind given the current supply chain quagmire we find ourselves in.

We do not believe there was a perfect storm that created the current supply chain crisis. Instead, the crisis highlights certain imperfections in the supply chains concerning lack of preparedness, capacity management, and regulation. The COVID experience highlights the need for a contingency response plan, something we should have learned from 2014, but one that employs a holistic perspective of the supply chain. A cure for expanding throughput capacity in Los Angeles/Long Beach may lead to a surge of freight into facilities whose owners have been minimizing slack and therefore cannot handle the surge. Marine terminal options should be identified and assessed in so far they are reasonable substitutes for the disrupted port, as should the other assets serving the supply chain. Pandemics are but just one risk; natural disasters, cyber and non-cyber attacks, labor strikes, and power outages, among others, are unpredictable events, which a contingency response plan is supposed to mitigate.

The coming decision-making challenge for asset owners will be centered on how much risk they are willing to take given the ongoing supply chain experience. Capacity minimization efforts have increased utilization rates to untenable levels. In the end, reductions in slack capacity cost shippers more and bog down marine terminals and warehouses. It seems the only winners in today's supply chain environment are the shipping lines, particularly given the freight rates on the east-west trades.

The Port of Los Angeles/Long Beach seems to be running out of options that would materially affect capacity availability. It may be time that the port recognizes this and should just say no to increased throughput opportunities after utilization rates approach congestion-risk thresholds. Having said this, the current growth trends may change as supply chains shift, with diversions to other U.S. port ranges and cross-border trade.

The merits of shipping alliance arrangements and the chassis legacy contracts should be revisited by regulators. Today, most economists agree that antitrust should be viewed as a consumer welfare prescription. The DOJ has stated that a practice monopolizes or tends to lessen competition if it harms consumers by reducing the value they would have enjoyed from the market absent these anticompetitive practices. We wonder why alliances and legacy contract practices 
have not been subjected to renewed scrutiny given they have evolved to restrain competition.

JIT logistics emphasized high capacity utilization as a measure of good performance. We don't believe this to be valid today. Slack capacity is key to providing supply chain resiliency, but this comes with a cost. Asset operators and companies that rely on them are being painfully reminded of the attributes of supply chain certainty and reliability and the added cost burden that lack of resiliency brings. Establishing a regulatory framework that ensures sufficient slack in the supply chain may be justified; certainly, with sufficient slack, Lucy and Ethel would not have to continue fighting a losing game.

Publisher's Note Springer Nature remains neutral with regard to jurisdictional claims in published maps and institutional affiliations. 